\title{
The Study and Analysis of Social Responsibility Education in Visual Communication Design Major
}

\author{
Xiaoyun Min \\ Leshan Normal University, Leshan, Sichuan 614000, China \\ Keywords: Visual Communication Design; students; social responsibility education

\begin{abstract}
In recent years, China's colleges and universities have successively set up the visual communication art design major and promoted the development of visual communication art. Therefore, it is necessary to recognize the nature of visual communication design, grasp its distinctive diversification characteristics, and realize the era of visual communication design. In the teaching of visual communication design, students' social responsibility education is very important. Teachers must recognize the importance of this education, and use the best level of work according to their creative status to improve students' social responsibility in visual communication design.
\end{abstract}

\section{Introduction}

In the education of colleges and universities, the visual communication design major is an important professional course. It has a certain influence on students' world outlook, outlook on life and values, and is conducive to cultivating students' sense of social responsibility. Visual communication design plays an important role in social development. People also recognize the importance of visual communication design. There are many applications of visual communication design in political propaganda, social welfare, and environmental protection.

\section{The Role of Visual Communication Design Major in the Development of Students' Social Responsibility}

\subsection{Visual Communication Design}

Visual Communication Design is also known as graphic design. In the newspapers, magazines, billboards, light boxes and many other areas, there are visual communication design applications. Visual communication design involves a lot of content, including advertising design, printing design, book binding design, poster poster design, product packaging design, corporate image design, display design, digital image design and so on. Although visual communication design originated from graphic design, its scope is relatively large. Multimedia technology has deepened the influence and penetration of art design [1]. At present, the visual communication design major in colleges and 
universities began to adapt to the needs of the era of innovation, and trained talents with an international design culture vision and Chinese design cultural characteristics. Therefore, cultivating students' social responsibility is the teaching goal of the visual communication design profession. In the visual communication design profession, students must have the concept of serving the society, understand the relevant laws and regulations, strengthen students' design innovation, language and language expression, and social communication skills, and have professional skills in graphic design such as advertising, display, media, and publishing. technical skills.

\subsection{Development Trend of Visual Communication Design Major}

The visual communication design is different from the traditional visual element design, including the auditory elements, and the increase of the sense of smell and touch is the focus of future development. Usually, a variety of knowledge is used in visual communication design, so students must grasp different knowledge disciplines. At present, the visual communication design profession has begun to focus on the penetration of the spirit of humanistic care, and its information dissemination is getting faster and faster, which can satisfy people's pursuit of innovation. With the improvement of our material living standards, spiritual enjoyment has become an important pursuit for people. We must change the requirements of visual communication design and break through the shackles of traditional design [2]. Nowadays, many visual communication designs have drawn on Chinese traditional culture, which is the promotion of traditional Chinese culture. Therefore, it also focuses on social responsibility. In the teaching of visual communication design, students should develop their sense of social responsibility according to their living environment, cultural background, level of education, and their own personalities, and promote the innovative development of visual communication design.

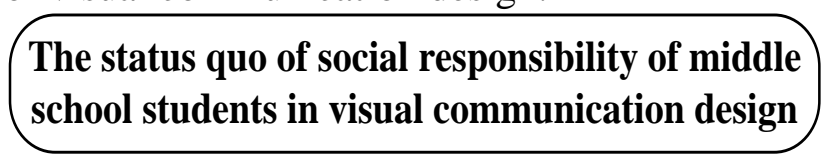

Visual Communication Design Students' Social Responsibility Training Objectives

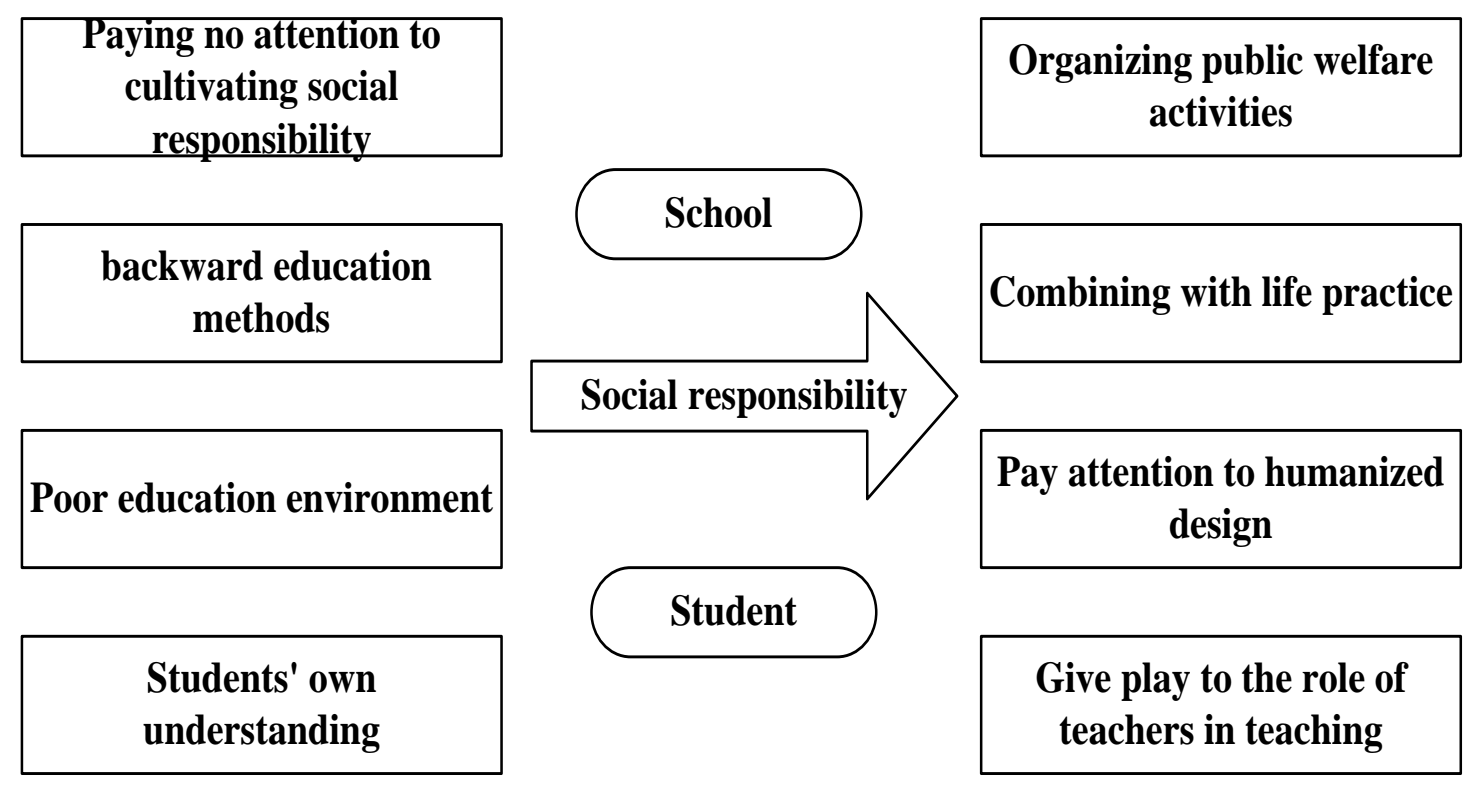

Fig. 1 School Education Visual Communication Design Student's Educational Mission 


\subsection{The Role of Visual Communication Design Major in the Development of Students' Social Responsibility}

\subsubsection{Improve students' ideological and moral qualities}

As an art and design major, visual communication design students are active in thinking, have a strong sense of self, and pay more attention to their own personality development. Students usually pay more attention to personal design, and they pay less attention to society. Therefore, they have weak social responsibilities, low ideological and political qualities, and are prone to bad living habits and learning habits. The visual communication design professional can enable students to pay attention to their living environment and education experience, guide students to recognize possible problems around themselves, and design works with more humanistic feelings through social responsibility to help improve students' ideological and moral qualities. [3].

\subsubsection{Help students fully understand themselves}

University art design students have long been immersed in the field of art design. They have little contact with outside art design works. They can't make scientific and reasonable evaluations of their own designs, and they are easily depressed and not good at self-expectations. Adjustment, denial of their own design capabilities, lack of confidence. The visual communication design professional can allow students to conduct accurate self-evaluation in the process of external sensory contact, help students establish a correct outlook on life and values, and clarify students' professional learning goals.

\subsubsection{Meet the social development needs}

Nowadays, the development process of society pays more attention to the professional skills and the moral qualities of professionals. The visual communication design professional will guide students to form a good professional ethics and ethos, help students adjust their emotions, correct their learning attitudes, and establish a good and healthy learning attitude for artistic creation. Only in this way can we meet the needs of social posts and meet the social development requirements.

\section{The Status of Social Responsibility of Visual Communication Design Students}

\subsection{No attention to cultivate social responsibility}

Many universities and colleges emphasize administrative management and light ideological theory education, making the visual communication design profession not attach importance to cultivating students' sense of social responsibility. After the class, the student union will only organize psychological counseling, health inspections, contradictions, extra-curricular activities, various award-winning appraisal activities, loan subsidies, etc., and will not integrate social responsibility [4]. The school staff also did not do a good job in cultivating social responsibility, and the human visual communication design students have unique personality and management difficulties. The ideological and political education carried out by the college is mainly combined with management and guidance. The education content of the visual communication design profession pays more attention to the teaching of professional content. The education of the students' world outlook, outlook on life and morality is less developed, which is not conducive to promoting the overall overall development of students' personal qualities. Students do not recognize the 
importance of social responsibility, and the visual communication design profession is out of touch with social responsibility.

\subsection{Backward education methods}

At present, the training of students in visual communication design majors in colleges and universities mainly depends on ideological and political education, and teaching methods are backward. The content of ideological and political education in the visual communication design major is small, and it mainly manifests as classroom education. Because the teacher's teaching in the classroom only pays attention to the professional explanation of the course, this is inconsistent with the fact that the art students have active thoughts and lively characters, so it is difficult to cultivate a sense of social responsibility. And after school students rarely actively participate in the process of social responsibility, so it is difficult to cultivate students' sense of social responsibility. Nowadays, one of the main tasks of the college student union is to help teachers manage students, integrate social responsibility into the activities of the student union, and carry out imagination and innovation while managing preaching, giving full play to the delicate and delicate features of art students.

\subsection{Poor education environment}

Although the development of the public media is getting faster and faster, and people's traditional understanding has been changed, the disorder of the public media has caused many art students to experience cognitive biases, the impact of values, disregard of authority and tradition, and low moral and cultural quality. This is not conducive to the study of art and cannot be responsible for its artistic creation. It will lead to wrong orientation. Moreover, the thinking of parents of many art students is still relatively backward. They did not realize the importance of cultivating their children's sense of social responsibility. They only paid attention to the immediate short-term interests and emphasized the students' professional skills learning, which was not conducive to their future career development and would easily lead to their personal comprehensiveness. Unbalanced quality. Many colleges and universities also only pay attention to the quality of teaching. They have not combined visual communication design teaching with the cultivation of social responsibility. The work of ideological and political education is poor [5]. Therefore, it is necessary to change the concept of education in colleges and universities, improve the understanding of the importance of teachers and students in ideological and political education, and integrate social responsibility into visual communication design.

\subsection{Students' own understanding}

Visual communication design students do not think deeply about the problem. They pay more attention to their own professional development, lack understanding of current affairs politics, and their ideological consciousness is not high, which affects the study of their natural ideological and political theories. Moreover, because of the visual communication design professional, students are affected by various ideas in the society. In their contact with society, their values are more diverse, their thoughts are more active and open, and they are more likely to accept new ideas. University students' values and world outlook are still developing. If they are affected by bad thoughts and behaviors, they will affect their future academic and career development. With the attraction of new things, the ability of discriminating visual communication design students is decreasing, and external factors are more likely to affect them, making their value orientation more complicated. Unlike other professional students, the ideals and beliefs of visual communication design students are ambiguous. 
They do not pay attention to theoretical professors in the classroom, making their cultural foundation weak and focusing only on social practice. The sense of social responsibility of visual communication design students needs to be improved, ignoring their own social responsibilities and focusing only on their professional development.

\section{Social Responsibility Training of Visual Communication Design Students}

\subsection{Organize public welfare activities}

Visual communication design institutes shall organize charitable activities, and encourage students to actively participate in public welfare undertakings organized by society and schools. Through the development of students' expertise, they will practice socialist core values in artistic creation and artistic communication, and assume their own social responsibilities. Of course, teachers can also increase the content of social practice in the teaching process, give students a topic, and allow students to create in practice. In this way, not only can we train students to shape their practical ability, but they can also develop their sense of social responsibility and promote the cultivation and cultivation of socialist core values so that students can truly appreciate the artistic value of the visual communication design profession and exert their positive energy [6].

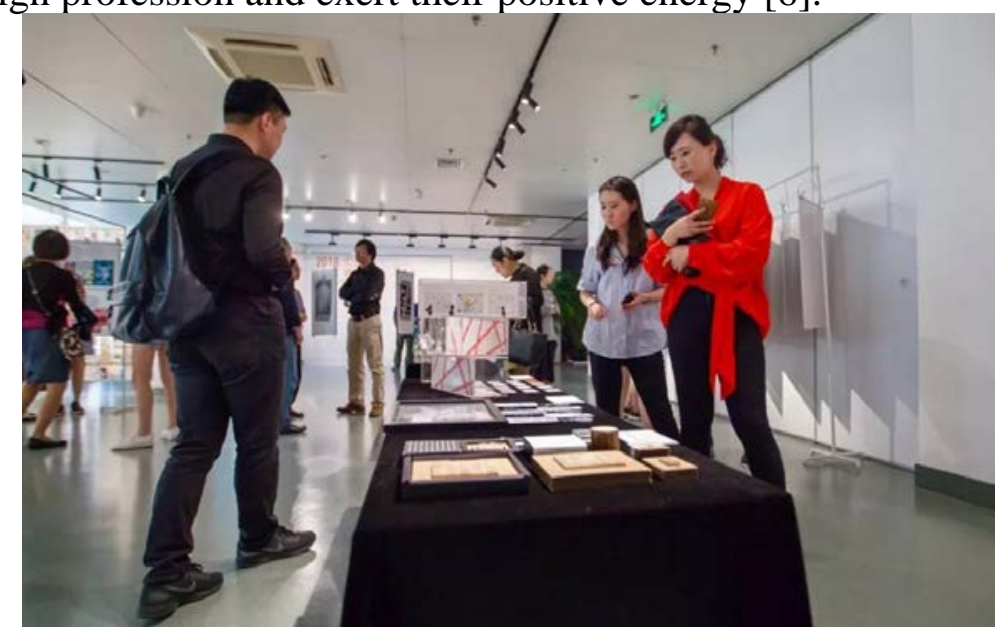

Fig. 2 School organization student works exhibition practice

\subsection{Combine with life practice}

In carrying out the teaching of visual communication design, the content of the teaching should be linked to the reality of life and ensure that it meets the design requirements of localization. In the design process, it is necessary to transform the old model elements with Chinese geographical features, and pass modern design concepts from them, and convey the modern information of the carriers from the old elements, so that students can feel the connotations of their works while experiencing their works. In this way, students can take into account creativity and social responsibility in practice, and use the social role of visual communication design. Therefore, students must create more designs that are popular among the people and integrate traditional Chinese culture with the development of the times, such as decoration and traditional designs, calligraphy, Chinese paintings, folk prints, folk paper-cuts, folk arts, and so on. The featured design. 


\subsection{Pay attention to humanized design}

With the development of social economy, humanized design and green development have become the theme of visual communication design. The visual communication design professional must assume its social responsibility, pay attention to the protection of natural life and full use of resources, and take people as the center. This visual communication design professional teaching will be more green science, in line with the requirements of environmental protection and ecological development. This is the requirement of human-oriented green design in the visual communication design profession, and it is also a concrete embodiment of its commitment to social responsibility. Through the integration of humanistic design concepts in the visual communication design profession, the unity of graphic design and ecological environment has been achieved, which is conducive to cultivating students' sense of social responsibility [7].

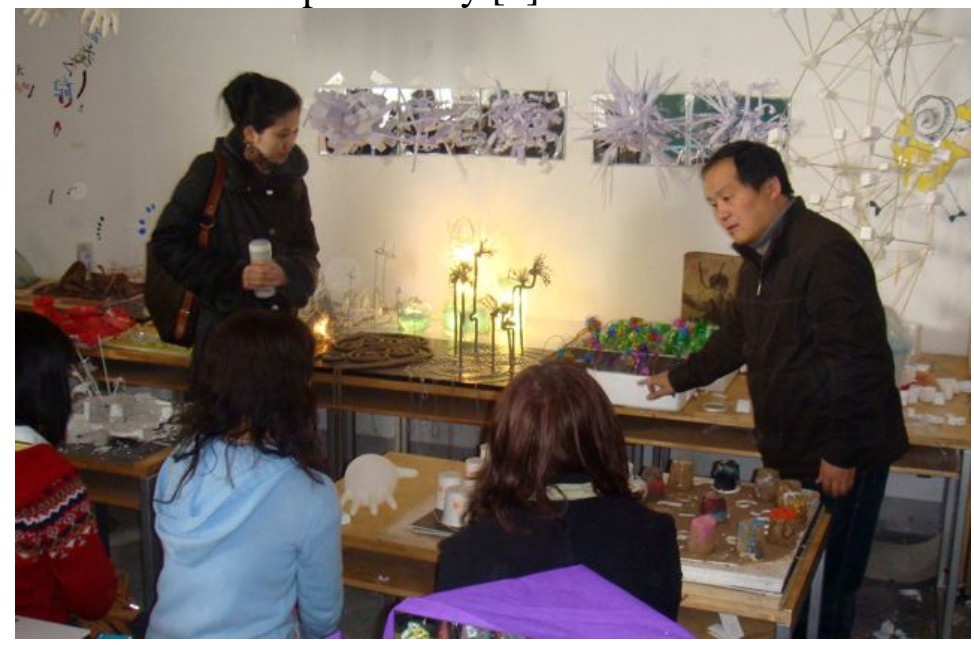

Fig. 3 Teachers should pay attention to the cultivation of humanity in teaching

\subsection{Give play to the role of teachers in teaching}

In the teaching of colleges and universities, all aspects of the teachers influence the students in a subtle way and exert different degrees of influence on their ideology and morality. Therefore, it is necessary to improve the ideological and moral qualities of teachers and strengthen their sense of social responsibility. In this way, in the visual communication design professional teaching, students can convey a concept of social responsibility and allow students to realize their connection with the visual communication design profession. In practical visual communication design, students will express this concept and assume their own social responsibility.

\section{Conclusion}

The goal of talent cultivation in colleges and universities is to cultivate high-quality and talented personnel. In the visual communication design profession, it is also necessary to focus on the cultivation of their teaching objectives and improve students' sense of social responsibility. Therefore, colleges and universities must change the traditional teaching concept of visual communication design professional, combine social needs and social responsibility, and pay attention to the cultivation of applied visual communication design talents. At the same time, colleges and universities should also do a good job of ideological and political education in the visual communication design profession, combine the student's ideological status to carry out 
people-oriented teaching, and enrich students' sense of social responsibility training methods, such as organizing charity events, increasing teaching practice, organizing teaching lecture halls, and so on. In this way, students can develop a sense of social responsibility in the visual communication design profession. In a mufti-angle ideological and political education, students can recognize the connection between the visual communication design profession and the society, and cultivate a good visual quality and professional vision. Communication design professionals.

\section{References}

[1] Jiang Siyu, et al. Analysis of several problems in the reform of graduation design of visual communication design professional. Studies of Fine Arts Education, Vol. 4 (2014) p.85.

[2] Zhang Shengli, et al. Analysis of the problems in the teaching of visual communication design and its solutions. Studies of Fine Arts Education, Vol. 16 (2014) p.124.

[3] Wu Xi, et al. Analysis of Social Responsibility in Visual Communication Professional Education. Journal of Tianjin Academy of Fine Arts, Vol. 2 (2014) p.97-98.

[4] Li Juan, Huang Hong, Lu Xiaogen, et al. Thinking about the cultivation of T-type creative talents. Art Education, Vol. 2 (2016) p.59-61.

[5] Wei Chaoxian, et al. On the Cultivation of Students' Creative Ability in Visual Communication Design Majors in Colleges and Universities. Art Education, Vol. 12 (2015) p.67.

[6] Song Hua, et al. On the role of school-enterprise cooperation in cultivating visual communication design students. Times Education, Vol. 9 (2015) p.24.

[7] Li Qi, et al. Study on the Social Responsibility Education for Visual Communication Design Students. Industrial Design, Vol. 10 (2017) p.116-117. 